Pesq. Vet. Bras. 36(9):826-830, setembro 2016

DOI: $10.1590 / \mathrm{S} 0100-736 \mathrm{X} 2016000900006$

\title{
Uso de antimicrobiano nanoparticulado para o tratamento da mastite subclínica de ovelhas de corte no período seco ${ }^{1}$
}

\author{
Raul C.M. Santana ${ }^{2 *}$, Luiz Francisco Zafalon², Humberto de M. Brandão ${ }^{3}$, \\ Guilherme A.F. Junior ${ }^{4}$, Lucas Eduardo Pilon ${ }^{4}$, Waldomiro B. Junior ${ }^{2}$, Rodrigo \\ Giglioti $^{4}$ e Vanessa Carla F. Mosqueira ${ }^{5}$
}

\begin{abstract}
Santana R.C.M., Zafalon L.F., Brandão H.M., Junior G.A.F., Pilon L.E., Junior W.B., Giglioti R. \& Mosqueira V.C.F. 2016. [Use of nanoparticulated antimicrobians to treat subclinical mastitis of ewes during the dry period.] Uso de antimicrobiano nanoparticulado para o tratamento da mastite subclínica de ovelhas de corte no período seco. Pesquisa Veterinária Brasileira 36(9):826-830. Unidade Pecuária Sudeste, Embrapa, Rodovia Washington Luiz Km 234 s/n, Caixa Postal 339, São Carlos, SP 13560-970, Brazil. E-mail: raul.mascarenhas@embrapa.br

Inflammation of the mammary gland is one of the main causes of losses in sheep-rearing. This study aimed to investigate the cure rates from treating subclinical mastitis after intramammary infusion of active antimicrobial agents as conventional formulations or as nanoparticles, at the time when the ewes are being dried off. A total of 584 mammary glands in 307 ewes in meat-producing herds located in São Carlos, São Paulo, Brazil, were analyzed. Prescreening of subclinical mastitis cases was done using the California mastitis test (CMT) and/or the somatic cell count (SCC). Microbiological analyses were performed to confirm the infectious etiology. The mammary glands with subclinical mastitis were distributed into three groups: G1 (control; mammary glands that did not receive any antimicrobial treatment); G2 (mammary glands to which $100 \mathrm{mg}$ of benzathine cloxacillin in conventional form were administered); and G3 (mammary glands to which 50mg of benzathine cloxacillin in nanoparticulate form were administered). The treatment applied to G3 was more efficient $(\mathrm{P}=0.047)$ in curing mammary glands with subclinical mastitis. Use of cloxacillin nanoparticles at the time when the ewes are being dried off helps to control infectious subclinical mastitis and reduces consequential losses among meat-producing herds.
\end{abstract}

INDEX TERMS: Nanoparticulated antimicrobians, nanocapsules, subclinical mastitis, sheep, dry period, drying-off, cloxacillin.

RESUMO.- A inflamação da glândula mamária é uma das principais causas de prejuízo na ovinocultura. Este estudo teve como objetivo investigar as taxas de cura do tratamento da mastite subclínica após infusão intramamária de princípio ativo antimicrobiano no momento da secagem, em formulações convencional e nanoparticulada. Os rebanhos estavam localizados em São Carlos, São Paulo, Brasil. Analisou-se um total de 584 glândulas mamárias de 307 ovelhas de aptidão para produção de carne. Triagem prévia dos casos subclíni-

\footnotetext{
${ }^{1}$ Recebido em 9 de dezembro de 2015.

Aceito para publicação em 24 de junho de 2016.

${ }^{2}$ Unidade Pecuária Sudeste, Empresa Brasileira de Pesquisa Agropecuária (Embrapa), Rodovia Washington Luiz Km 234 s/n, Caixa Postal 339, São Carlos, SP 13560-970, Brasil. *Autor para correspondência: raul. mascarenhas@embrapa.br
}

cos de mastite foi efetuada por meio do California Mastitis Test (CMT) e/ou da contagem de células somáticas (CCS). Análises microbiológicas foram realizadas para confirmação da etiologia infecciosa. As glândulas mamárias com mastite subclínica foram distribuídas em três grupos: G1 (Controle; glândulas mamárias que não receberam tratamento antimicrobiano); G2 (glândulas mamárias em que foi administrado $100 \mathrm{mg}$ de cloxacilina benzatina em estrutura convencional) e G3 (glândulas mamárias em que foi administrado $50 \mathrm{mg}$ de

\footnotetext{
3 Embrapa Gado de Leite, Rua Eugênio do Nascimento 610, Juiz de Fora, MG 36038-330, Brasil.

${ }^{4}$ Universidade Estadual Paulista (Unesp), Via de acesso Prof. Paulo Donato Castellane s/n, Jaboticabal, SP 14884-900, Brasil.

${ }^{5}$ Departamento de Farmácia, Escola de Farmácia, Universidade Federal de Ouro Preto (UFOP), Ouro Preto, MG 35400000, Brasil.
} 
cloxacilina benzatina em estrutura nanoencapsulada). 0 tratamento aplicado ao G3 mostrou-se mais eficiente $(\mathrm{P}=0,047)$ na cura de glândulas mamárias com mastite subclínica. 0 uso da cloxacilina nanoencapsulada no momento da secagem de ovelhas de corte auxilia no controle da mastite subclínica infecciosa e reduz os prejuízos consequentes.

TERMOS DE INDEXAÇÃO: Antimicrobiano nanoparticulado, nanoparticulas, mastite subclínica, ovelhas de corte, período seco, cloxacillina, secagem.

\section{INTRODUÇÃO}

A mastite está entre os problemas sanitários que mais afetam a saúde de ovelhas de corte, acarretando descarte de ovelhas e morte prematura das crias de ovelhas afetadas pela doença (Verissímo et al. 2010). No momento da desmama dos cordeiros, o procedimento de secagem da ovelha faz parte da gestão da saúde da glândula mamária. No entanto, existe uma carência de estudos sobre o uso de tratamentos antimicrobianos nesta espécie durante o período seco em rebanhos brasileiros, sobretudo em raças de corte. A formulação do antibiótico, a concentração ideal e a forma de administração do fármaco capazes de curar a infecção subclínica durante a fase da secagem são desconhecidas.

A quantidade de antimicrobianos normalmente utilizada para o tratamento de infecções é mais elevada que a dose necessária para inativar os organismos patogênicos, o que favorece a produção de efeitos citotóxicos. Para uma terapia antimicrobiana de sucesso, a dose deve ser a mínima necessária, a fim de evitar os efeitos secundários já relatados em literatura oriundos de citotoxidade direta ou hipersensibilidade alérgica como nefrite intersticial (Saha et al. 2007).

Muitos antimicrobianos em formulações tradicionais apresentam pouca chance de penetração em altas concentrações nos neutrófilos e, quando presente no ambiente intracelular, apresentam uma parte não biodisponível ligada a componentes celulares, o que difilculta a eliminação de focos de infecção intracelular e favorece recidivas pós-tratamentos (Bambeke et al. 2006).

Diferentes antimicrobianos têm sido recomendados na terapia intramamária (Naccari et al. 2003). Entretanto, são poucos os estudos conduzidos na investigação do perfil de sensibilidade da mastite ovina e são escassos ensaios clínicos controlados sobre a cura clínica e bacteriológica após o tratamento intramamário da ovelha (Bergonier \& Berthelot 2003).

Diversas pesquisas foram realizadas nos últimos anos avaliando vetores de liberação de fármacos em sítios específicos quanto a eficiência e citotoxicidade (Bilensoy et al. 2008, Toti et al. 2011, Sanyasi et al. 2016). Sistemas nanoparticulados têm sido propostos para a internalização de agentes antimicrobianos no ambiente intracelular, contribuindo assim para aumentar o índice terapêutico de antimicrobianos nos locais das infecções (Lecároz et al. 2006).

As nanopartículas representam formas inovadoras no tratamento de doenças por sua escala de tamanho ser semelhante à de moléculas biológicas (Wiesenthal et al. 2011). Dentre suas vantagens, apresentam-se como veículos de fármacos de alta estabilidade, elevada capacidade de carga transportada, possibilidade de incorporação de subs- tâncias hidrofílicas e hidrofóbicas conjuntamente (Irache et al. 2011), capacidade em superar diversas barreiras biológicas e se localizar no tecido alvo. As nanopartículas podem ser um carreador ou a própria droga ativa e fornecem perfis de liberação controlada (Wong \& Liu 2012).

As nanopartículas poliméricas são estruturalmente estáveis e podem ser sintetizadas com distribuições de tamanhos mais nítidos. As propriedades da partícula tais como o tamanho, potencial zeta e o perfil de liberação do fármaco podem ser ajustadas precisamente escolhendo diferentes comprimentos de polímeros, surfactantes e solventes orgânicos durante a síntese. A superfície de nanopartículas poliméricas geralmente contém grupos funcionais que podem ser modificados quimicamente (Zhang et al. 2010).

Este estudo teve como objetivo investigar as taxas de cura do tratamento da mastite subclínica após infusão intramamária de princípio ativo antimicrobiano no momento da secagem, em formulações convencional e nanoparticulada.

\section{MATERIAL E MÉTODOS}

Local, animais e coleta de amostras experimentais. 0 trabalho foi realizado em uma propriedade localizada no município de São Carlos, São Paulo, pertencente à Embrapa Pecuária Sudeste e com aprovação da sua Comissão de Ética do Uso de Animais (CEUA; protocolo 03/2012). Analisou-se um total de 584 metades mamárias de ovelhas de aptidão para produção de carne, 349 das quais pertencentes a 181 ovelhas de um rebanho da raça Santa Inês e outras 235 metades mamárias de 126 ovelhas de rebanho da raça Morada Nova. Todos os animais foram mantidos em piquetes de capim Coast-cross e Brachiaria decumbens e suplementados com fornecimento diário de silagem de milho, sal mineral e água à vontade durante todo o período do experimento. As amostras de leite foram coletadas 10 dias antes do desmame, no dia do parto (amostras de animais submetidos a tratamento, destinadas à análise de resíduo) e entre 10 e 15 dias pós-parto na estação de parição consecutiva. Foi coletada uma amostra de leite ( $2 \mathrm{~mL}$ ) de cada glândula para a realização imediata do California Mastitis Test (CMT), uma amostra de $60 \mathrm{~mL}$ de leite de cada glândula encaminhadas para a contagem de células somáticas (CCS) em aparelho eletrônico, Somacount 300 (Bentley Instruments ${ }^{\circledR}$ ) no laboratório da Clínica do Leite, localizado na cidade de Piracicaba, São Paulo e, de forma asséptica, duas amostras contendo $5 \mathrm{~mL}$ de leite de cada mama da ovelha destinadas aos exames microbiológicos.

Diagnóstico microbiológico e determinação da sensibilidade aos antimicrobianos. 0 diagnóstico microbiológico da mastite subclínica foi realizado nos laboratórios da Embrapa Pecuária Sudeste. Efetuou-se a semeadura das amostras de leite sobre a superfície de placas de Petri em ágar acrescido de sangue ovino desfibrinado a 5\% e ágar MacConkey, incubadas em condições de aerobiose a $37^{\circ} \mathrm{C}$. A leitura das placas foram realizadas às 24, 48 e 72 horas de incubação. Foram observadas as características macroscópicas das colônias e realizada identificação posterior segundo as características morfotintoriais e bioquímicas (Koneman et al. 2001).

Os micro-organismos isolados foram submetidos aos testes de sensibilidade in vitro a partir da técnica de difusão com disco em placas de ágar Müeller-Hinton ou Müeller-Hinton-sangue, na dependência do micro-organismo isolado, frente à oxacilina (OXA$1 \mu \mathrm{g}$ ). Utilizou-se conjuntamente o disco de cefoxitina (CFO-30 $\mu \mathrm{g}$ ) quando isolados Staphylococcus aureus e $S$. coagulase-negativos. A aferição dos halos de inibição foi feita segundo Clinical and Laboratory Standards Institute (CLSI 2012). 
As glândulas mamárias que não apresentavam anormalidades clínicas e bacteriologicamente positivas, com escore positivo ao CMT a partir de $1+$ e/ou CCS $>2,5 \times 10^{5}$ células/mL de leite (Pengov 2001) foram consideradas positivas para mastite subclínica. As glândulas mamárias que não apresentaram anormalidades clínicas e foram bacteriologicamente negativas, com escore negativo ao CMT e CCS $<2,5 \times 10^{5}$ células/mL foram consideradas saudáveis.

Tratamentos experimentais. As metades mamárias infectadas e que, posteriormente, foram avaliadas estiveram distribuídas nos seguintes grupos: $\mathrm{G} 1$ (Controle, $\mathrm{n}=25$ ), composto por metades mamárias com mastite subclínica que não receberam tratamento antimicrobiano intramamário; G2 $(n=25)$, composto por metades mamárias com mastite subclínica tratadas com antimicrobiano Convencional (100mg de cloxacilina benzatina/ $10 \mathrm{~mL}$ ); G3 (n=21), formado por metades mamárias com mastite subclínica em que foi administrado o antimicrobiano nanoencapsulado (50mg de cloxacilina benzatina/86mL). Somente as metades mamárias infectadas por micro-organismos sensíveis ao princípio ativo utilizado, verificado por meio do teste de sensibilidade in vitro, foram submetidas aos tratamentos, excluindo-se assim as metades mamárias infectadas com micro-organismos do grupo das enterobactérias.

Algumas ovelhas que apresentaram mastite subclínica e inicialmente foram triadas e submetidas aos tratamentos foram retiradas da análise devido aos seguintes motivos: oito ovelhas (duas do G1, duas do G2 e quatro do G3) não apresentaram prenhez positiva, duas ovelhas (uma do G1 e uma do G3) apresentaram abortos e outras três (duas do G1 e uma do G3) vieram a óbito, impossibilitando suas avaliações.

0 antimicrobiano nanoencapsulado foi produzido nos laboratórios da Embrapa Gado de Leite, localizado em Juiz de Fora, Minas Gerais, Brasil, de acordo com a metodologia descrita na patente publicada no US2013/0189368A1. As nanopartículas confeccionadas foram compostas por um núcleo oleoso formado por polímero hidrofóbico associado à cloxacilina benzatina e coberto por uma membrana polimérica catiônica dispersa em um meio aquoso externo. A concentração da cloxacilina benzatina na solução oriunda do processo de nanoencapsulação foi determinada por cromatografia líquida de alta eficiência com detector de arranjos de diodos (CLAE-DAD) durante a validação do método para obtenção da respectiva patente. Após a encapsulação, a solução foi congelada a $-85^{\circ} \mathrm{C}$ por 24 horas e submetida à secagem por liofilização. 0 soluto foi resuspendido em água MilliQ para concentração final de $50 \mathrm{mg}$ de cloxacilina benzatina/86mL de solução, baseando-se no volume de aplicação de menor diluição possível do fármaco, que não favorecesse aglutinações macroscópicas e que fosse suportado pelos limites físicos da glândula mamária ovina.

0 antimicrobiano convencional foi confeccionado por meio da solubilização de $100 \mathrm{mg}$ de cloxacilina benzatina estéril em triglicerídeo de ácido cáprico/ caprílico grau farmacêutico, em volume total de $10 \mathrm{~mL}$ e acondicionado em seringas plásticas estéreis de mesmo volume.

O desmame dos cordeiros foi realizado 100 dias após o nascimento em média. Três dias após o desmame, o úbere foi submetido ao esvaziamento manual completo, antissepsia com álcool isopropílico $70 \%$ dos esfíncteres dos tetos e, posteriormente, ocorreram os tratamentos intramamários com infusão antimicrobiana. Utilizou-se a estrutura flexível de um cateter intravenoso tamanho no 20 (1,1mm x48mm; calibre x comprimento) estéril para cada tratamento intramamário, adentrando apenas meio centímetro ao canal do teto.

Determinação da cura microbiológica e análise de resíduos. Na lactação posterior, as metades mamárias dos diferentes grupos experimentais foram classificadas como "curadas", quan- do não houve o isolamento de quaisquer micro-organismos e "não curadas", quando o mesmo patógeno presente antes do tratamento foi isolado posteriormente. Metades mamárias reinfectadas, ou seja, onde houve o aparecimento de um micro-organismo diferente do isolado na fase de secagem, foram consideradas não curadas. Os animais que apresentaram evolução para mastite clínica antes dos tratamentos experimentais foram retirados do estudo.

Amostras de colostro obtidas imediatamente após o parto dos animais dos grupos de tratamentos foram destinadas a investigação da presença de resíduos por CLAE-DAD.

Análise estatística. Na análise dos dados, utilizou-se o pacote estatístico SAS (2002/2003). 0 teste de qui-quadrado foi empregado para estudar as distribuições dos casos curados e não curados nos grupos testados (G1, G2 e G3). Os valores significativos de qui-quadrado que estiveram próximos aos valores tabelados foram ajustados de acordo com a correção de continuidade de Yates (Sampaio 1998).

\section{RESULTADOS E DISCUSSÃO}

As prevalências da mastite subclínica nos animais nas diversas estações de parições do rebanho variaram de 14,8\% a 41,2\%. Das 307 ovelhas avaliadas, 91 (29,6\%) apresentaram mastite subclínica em pelo menos uma das metades mamárias. As frequências dos agentes etiológicos nas infecções mamárias subclínicas encontram-se descritas no Quadro 1.

Foram examinadas neste estudo 584 metades mamárias. Dessas, $101(17,3 \%)$ foram positivas para mastite subclínica infecciosa, sendo que $62(17,8 \%)$ e $39(16,6 \%)$ foram diagnósticadas em ovelhas das raças Santa Inês e Morada Nova, respectivamente.

Staphylococcus coagulase-negativos foram os agentes etiológicos predominantes nas infecções mamárias observadas neste estudo (56,4\%). Silva et al. (2010) e Guaraná et al. (2011) constataram a presença de SCN na maioria das infecções subclínicas em metades mamárias de ovelhas de corte com ocorrências de 26,9\% e 65,9\%, respectivamente.

No presente estudo, $16,8 \%$ das infecções foram causadas por micro-organismos pertencentes ao grupo das enterobactérias. 0 elevado percentual de metades mamárias infectadas com enterobactérias denota a importância desses agentes na patogenia da doença e ratifica a importância da adoção de medidas higiênicas nas instalações onde são ma-

Quadro 1. Frequência de agentes etiológicos em infecções mamárias puras ou mistas em ovelhas de aptidão para produção de carne

\begin{tabular}{|c|c|c|c|c|c|c|}
\hline \multirow[t]{2}{*}{ Micro-organismos } & \multicolumn{2}{|c|}{$\begin{array}{l}\text { Mamas de } \\
\text { ovelhas SI }\end{array}$} & \multicolumn{2}{|c|}{ 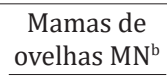 } & \multicolumn{2}{|c|}{$\begin{array}{c}\text { Total das } \\
\text { mamas }\end{array}$} \\
\hline & $\mathrm{N}$ & $\%$ & $\mathrm{~N}$ & $\%$ & $\mathrm{~N}$ & $\%$ \\
\hline $\mathrm{SCN}^{\mathrm{c}}$ & 33 & 53,3 & 24 & 61,6 & 57 & 56,4 \\
\hline Enterobactérias & 12 & 19,4 & 5 & 12,8 & 17 & 16,8 \\
\hline Streptococcus spp. & 8 & 12,9 & 2 & 5,1 & 10 & 9,9 \\
\hline Micrococcus spp. & 3 & 4,8 & 3 & 7,7 & 6 & 5,9 \\
\hline Staphylococcus aureus & 1 & 1,6 & 3 & 7,7 & 4 & 4 \\
\hline Corynebacterium spp. & 2 & 3,2 & 2 & 5,1 & 4 & 4 \\
\hline Streptococcus spp. + SCN & 2 & 3,2 & 0 & 0 & 2 & 2 \\
\hline $\mathrm{SCP}^{\mathrm{d}}$ & 1 & 1,6 & 0 & 0 & 1 & 1 \\
\hline Total & 62 & 100,0 & 39 & 100,0 & 101 & 100,0 \\
\hline
\end{tabular}

${ }^{\mathrm{a} S I}=$ Ovelhas da raça Santa Inês; ${ }^{\mathrm{b}} \mathrm{MN}$ = Ovelhas da raça Morada Nova; 'SCN = Staphylococcus coagulase-negativos; ${ }^{\mathrm{d} S C P}=$ Staphylococcus coagulase-positivos. 
nejadas ovelhas em lactação, a exemplo da remoção diária de dejetos. Diferentemente, Silva et al. (2010) e Coutinho et al. (2006) atribuíram relevância maior a $S$. aureus quando comparado às enterobactérias, presente em 15,4\% e 15,2\% dos casos de mastites subclínicas infecciosas, respectivamente. Os $S$. aureus também são associados à presença de sinais clínicos em mastites crônicas (Marogna et al. 2010) e comumente responsável por mastite superaguda (Bergonier \& Berthelot 2003).

As metades mamárias infectadas e avaliadas após os tratamentos foram distribuídas conforme apresentado no Quadro 2.

O cateter utilizado para realizar a infusão intramamária do fármaco mostrou-se adaptado à anatomia da espécie não desencadeando lesões visíveis aos esfíncteres do teto e permitiu uma adequada velocidade de passagem do medicamento. As metades mamárias acometidas por mastites subclínicas apresentaram dimensões limites capazes de suportar um volume máximo de $86 \mathrm{~mL}$, o que limita a utilização de quantidades maiores da cloxacilina benzatina nanoencapsulada empregada neste trabalho, a qual não permitiu uma maior concentração com ausência de aglutinações. As taxas de cura da mastite subclínica ovina após os tratamentos antimicrobianos à secagem estão apresentadas no Quadro 3.

O processo inflamatório na glândula mamária desencadeado em resposta a um micro-organismo invasor pode ser efetivo no combate à infecção e a mama ovina pode apresentar auto-cura. A taxa de cura espontânea observada nas metades mamárias com mastite subclínica no Grupo Con-

\section{Quadro 2. Distribuição das glândulas mamárias com mastite subclínica nos grupos experimentais de acordo com os micro-organismos isolados}

\begin{tabular}{|c|c|c|c|c|c|c|}
\hline \multirow[t]{3}{*}{ Micro-organismos } & \multicolumn{6}{|c|}{ Grupos experimentais } \\
\hline & \multicolumn{2}{|c|}{ G1 } & \multicolumn{2}{|c|}{ G2 } & \multicolumn{2}{|c|}{ G3 } \\
\hline & $\mathrm{N}$ & $\%$ & $\mathrm{~N}$ & $\%$ & $\mathrm{~N}$ & $\%$ \\
\hline $\mathrm{SCN}^{\mathrm{a}}$ & 16 & 64,0 & 18 & 72,0 & 15 & 71,43 \\
\hline Streptococcus spp. & 6 & 24,0 & 1 & 4,0 & 1 & 4,76 \\
\hline Micrococcus spp. & 1 & 4,0 & 3 & 12,0 & 1 & 4,76 \\
\hline Staphylococcus aureus & 1 & 4,0 & 2 & 8,0 & 1 & 4,76 \\
\hline Corynebacterium spp. & 0 & 0,0 & 0 & 0,0 & 2 & 9,53 \\
\hline Streptococcus spp. + SCN & 1 & 4,0 & 1 & 4,0 & 0 & 0,0 \\
\hline $\mathrm{SCP}^{\mathrm{b}}$ & 0 & 0,0 & 0 & 0,0 & 1 & 4,76 \\
\hline Total & 25 & 100,0 & 25 & 100,0 & 21 & 100,0 \\
\hline
\end{tabular}

aSCN: Staphylococcus coagulase-negativos; 'SCP: Staphylococcus coagulase-positivos; G1: Grupo Controle; G2: Infusão de antimicrobiano convencional; G3: Infusão de antimicrobiano nanoencapsulado.

Quadro 3. Taxas de cura obtidas para mamas de ovelhas nos grupos testados

\begin{tabular}{|c|c|c|c|c|c|c|}
\hline \multirow[t]{2}{*}{ Grupos } & \multicolumn{2}{|c|}{ Mamas curadas } & \multicolumn{2}{|c|}{ Mamas não curadas } & \multicolumn{2}{|c|}{ Total } \\
\hline & $\mathrm{N}$ & $\%$ & $\mathrm{~N}$ & $\%$ & $\mathrm{~N}$ & $\%$ \\
\hline $\mathrm{G} 1^{\mathrm{a}}$ & 6 & $24,0 \mathrm{a}$ & 19 & $76,0 \mathrm{c}$ & 25 & 35,2 \\
\hline $\mathrm{G} 2^{\mathrm{b}}$ & 6 & $24,0 \mathrm{a}$ & 19 & $76,0 \mathrm{c}$ & 25 & 35,2 \\
\hline $\mathrm{G}^{\mathrm{c}}$ & 11 & $52,4 \mathrm{~b}$ & 10 & $47,6 \mathrm{~d}$ & 21 & 29,6 \\
\hline Total & 23 & 32,4 & 48 & 67,6 & 71 & 100,0 \\
\hline
\end{tabular}

${ }^{1}$ Grupo Controle; ${ }^{2}$ Mamas tratadas com cloxacilina convencional; ${ }^{3}$ Mamas tratadas com cloxacilina nanoencapsulada; Valores com letras diferentes dentro da mesma coluna correspondem à diferença significativa $(\mathrm{P}<0,05)$. trole foi de $24 \%$ (seis glândulas mamárias). 0 resultado é superior ao 6,5\% de Chaffer et al. (2003).

0 emprego de antimicrobiano nanoencapsulado para tratamento da mastite subclínica em ovelhas de corte realizado neste trabalho é pioneiro, não havendo ensaios clínicos similares até o presente momento. A eficiência da cloxacilina benzatina nanoencapsulada foi superior quando comparados os diferentes grupos ( $\mathrm{P}=0,047)$, mesmo com o emprego de metade da dose do antimicrobiano no estado livre.

O uso da cloxacilina nanoencapsulada no momento da secagem promoveu a cura microbiológica de $52,4 \%$ das glândulas mamárias submetidas ao tratamento. Seu emprego mostrou-se eficaz na aliminação de bactérias sensíveis a este antimicrobiano. 0 processo de nanoencapsulação descrito neste trabalho foi capaz de melhorar a eficácia da cloxacilina benzatina contra infecções mamárias causadas por bactérias e reduzir a quantidade utilizada desse princípio ativo. A utilização de baixas concentrações que sejam eficazes se faz necessária à medida que os antibióticos podem desencadear morte celular quando a concentração extracelular atinge níveis suficientemente elevados e o tempo de exposição é muito prolongado (Barcia-Macay et al. 2006).

$\mathrm{Na}$ escassez de ensaios in vivo, diversos autores têm relatado resultados de testes in vitro comparando antimicrobianos nanoencapsulados e sua forma livre. Toti et al. (2011) verificaram que a nanoencapsulação da azitromicina e da rifampicina utilizando polímeros biodegradáveis causou aumento das concentrações dos antimicrobianos no espaço intracelular que, em combinação com o processo de liberação prolongada, pode ser responsável pela maior eficácia no sítio de infecção de Chlamydia trachomatis e Chlamydia pneumoniae.

0 processo de confecção do antimicrobiano nanoencapsulado utilizado para o tratamento das metades mamárias do Grupo 3 apresentou uma eficiência de $87 \%$. 0 percentual do fármaco em forma livre (13\%) é capaz de iniciar rapidamente o combate aos micro-organismos mais expostos, enquanto que o antimicrobiano em nanocápsulas promove penetração mais eficiente nos locais de infecção menos acessíveis à forma livre do fármaco, como o ambiente intracelular dos macrófagos, e possui o princípio ativo protegido da degradação precoce ocasionando a liberação controlada (Wong \& Liu 2012).

Chaffer et al. (2003), após o uso de antimicrobiano à base de benzilpenicilina, nafcilina e dihidroestreptomicina em formas livres no período seco em ovelhas leiteiras, observaram taxa de cura de $64,9 \%$, superior às encontradas no presente estudo. Ressalta-se que a administração intramamária foi de dose confeccionada para uso em glândula bovina. Adicionalmente, as dosagens administradas via intramamária neste trabalho correspondem 1/6 (100 mg de clozacilina benzatina) e 1/12 (50 mg de cloxacilina benzatina) da dosagem dos antimicrobianos produzidos com este princípio ativo que estão disponíveis comercialmente no Brasil para uso em vacas no momento da secagem.

Kiossis et al. (2013) ao realizarem tratamentos intramamários em ovelhas com produto de uso para bovinos contendo benzilpenicilina, nafcilina e dihidroestreptomici- 
na, apesar de verificarem redução da CCS no leite, não observaram benefício na eliminação de infecções mamárias causadas por ECN.

Das metades mamárias não curadas dos animais experimentais, quatro $(21,1 \%)$ do Grupo Controle, três $(15,8 \%)$ do Grupo 2 e uma (10\%) do Grupo 3 evoluíram para mastite clínica na lactação subsequente. Há uma associação da ocorrência de mastite clínica a partir de casos antecedentes de mastite subclínica. Glândulas mamárias com infeccções subclínicas não curadas podem apresentar evolução das lesões e, consequentemente, aumento dos prejuizos.

As matrizes apresentaram intervalo médio entre partos de 260 dias. Em nenhuma amostra foi detectado resíduo de cloxacilina a partir do limite de quantificação da técnica de $1,0 \mathrm{mg} / \mathrm{L}$. Apesar de não ter sido detectada a cloxacilina no colostro ovino, a investigação de resíduos na carne também deve ser efetuada visando a segurança alimentar humana.

\section{CONCLUSÕES}

O emprego de antimicrobiano no momento da secagem de ovelhas de corte auxilia no controle da mastite subclínica.

A nanoencapsulação da cloxacilina aumenta sua eficácia in vivo contra micro-organismos sensíveis presentes em infecções mamárias ovinas, das quais Staphylococcus spp. coagulase-negativos são os principais agentes etiológicos.

Agradecimentos.- À Fundação de Amparo à Pesquisa do Estado de São Paulo/FAPESP (Processo n²012/03847-1), pelo financiamento deste trabalho.

\section{REFERÊNCIAS}

Bambeke F.V., Barcia-Macay M., Lemaire S. \& Tulkens P.M. 2006. Cellular pharmacodynamics and pharmacokinetics of antibiotics: current views and perspectives. Curr. Opin. Drug Discov. Develop. 9(2):218-230.

Barcia-Macay M., Seral C., Mingeot-Leclercq M., Tulkens P.M. \& Van Bameke F. 2006. Pharmacodynamic evaluation of the intracellular activities of antibiotics against Staphylococcus aureus in a model of THP-1 macrophages. Antimicrob. Agents Chemother. 50(3):841-851.

Bergonier D. \& Bertethelot X. 2003. New advances in epizootiology and control of ewe mastitis. Livest. Prod. Sci. 79:1-16.

Bilensoy E., Gurkaynak O., Dogan L.A. \& Hincal A.A. 2008. Safety and efficacy of amphiphilic $\beta$-ciclodextrin nanoparticles for paclitaxel delivery. Int. J. Pharmaceut. 347:163-170.

Chaffer M., Leitner G., Zamir S., Winkler M., Glikman A., Ziv N. \& Saran A. 2003. Efficacy of dry-off treatment in sheep. Small Rumin. Res. 47:11-16.

CLSI 2012. Performance standards for antimicrobial susceptibility testing, twenty-second informational supplement. Document M100-S22, Clinical and Laboratory S tandards Institute, Wayne, PA, 32(3):1-184. Disponível em <http://antimicrobianos.com.ar/ATB/wp-content/uploads/2012/11/M100S22E.pdf>. Acesso em Sept. 28, 2013.

Coutinho D.A., Costa J.N., Ribeiro M.G. \& Torres J.A. 2006. Etiologia e sensibilidade antimicrobiana in vitro de bactérias isoladas de ovelhas da raça Santa Inês com mastite subclínica. Revta Bras. Saúde Prod. Anim. $7(2): 139-151$.

Guaraná E.L.S., Santos R.A., Campos A.G.S.S., Silva N.S., Afonso J.A.B. \& Mendonça C.L. 2011. Dinâmica celular e microbiológica do leite de ovelhas Santa Inês acompanhadas durante a lactação. Pesq. Vet. Bras. 31(10): 851-858.

Irache J.M., Esparza I., Gamazo C., Agueros M. \& Espuelas S. 2011. Nanomedicine: novel approaches in human and veterinary therapeutics. Vet. Parasitol. 180(1/2):1-25.

Kiossis E., Brozos C.N., Petridou E., Zdragas A., Papadopulos T.H. \& Boscos C. 2013. Study on the possible survival of Staphylococcus chromogenes through the dry period in dairy ewes. Small Rumin. Res. 115:124-129.

Koneman E.W., Allen S.D., Janda W.M., Schhreckenberger P.C. \& Winn Junior W.C.W. 2001. Diagnóstico microbiológico: texto e atlas colorido. 5a ed. Medsi, Rio de Janeiro. 1465p.

Lecároz C., Blanco-Pietro M.J., Burrell M.A. \& Gamazo C. 2006. Intracellular killing of Brucella melitensis in human macrophages with microsphere-encapsulated gentamicin. J. Antimicrob. Chemother. 58(3):549-556.

Marogna G., Rolesu S., Lollai S., Tola S. \& Leori G. 2010. Clinical findings in sheep farms affected by recurrent bacterial mastitis. Small Rumin. Res. 88(2/3):119-125.

Naccari F., Martino D., Giofre F., Passantino A. \& De Montis P. 2003. Therapeutic efficacy of tilmicosin in ovine mammary infections. Small Rumin. Res. 47:1-9.

Pengov A. 2001. The role of coagulase-negative Sthaphylococcus spp. and associated somatic cell counts in the ovine mammary gland. J. Dairy Sci. 84:572-574

Saha B., Bhattacharya J., Mukherjee A., Ghosh A.K., Santra C.R., Dascupta A.K. \& Karmakar P. 2007. In vitro structural and functional evaluation of gold nanoparticles conjugated antibiotics. Nanoscale Res. Lett. 2:614622.

Sampaio I.B.M. 1998. Estatística Aplicada à Experimentação Animal. Fundação de Ensino e Pesquisa em Medicina Veterinária e Zootecnia, Belo Horizonte. 221p.

Sanyasi S., Majhi R.K., Kumar S., Mishra M., Ghosh A., Suar M., Satyam P.V., Mohapatra H., Goshwami C. \& Goswami L. 2016. Polysaccharide-capped silver nanoparticles inhibit biofilm formation and eliminate multi-drug-resistant bacteria by disrupting bacterial cytoskeleton with reduced cytotoxicity towards mammalian cells. Scient. Reports 6:1-16.

Silva N.S., Silveira F.A.S., Pinhiro C.P., Sousa M.G.S., Oliveira C.M.C., Mendonça C.L., Duarte M.D. \& Barbosa J.D. 2010. Etiologia e perfil de sensibilidade de bactérias isoladas de ovelhas com mastite na região nordeste do estado do Pará. Pesq. Vet. Bras. 30(12):1043-1048.

Toti U.S., Guru B.R., Hall M., McPharlin C.M., Wykes S.M., Panyam J. \& Whittum-Hudson J.A. 2011. Targeted delivery of antibiotics to intracellular chlamydial infections using PLGA nanoparticles. Biomaterials 32:66066613.

Verissímo C.J., Zafalon L.F., Otsuk I.P. \& Nassar A.F.C. 2010. Prejuízos causados pela mastite em ovelhas Santa Inês. Arqs Inst. Biológico, São Paulo, 77(4):583-591.

Wiesenthal A., Juntert L., Wang S., Wickliffe J. \& Wilkerson M. 2011. Nanoparticles: small and mighty. Int. J. Dermatology 50:247-254.

Wong K.K.Y. \& Liu X.L. 2012. Nanomedicine: a primer for surgeons. Pediatr. Surg. Int. 28:943-951.

Zhang L., Pornpattanagkul D., Hu C.M.J. \& Huang C.M. 2010. Development of nanoparticles for antimicrobial drug delivery. Curr. Med. Chemistry 15:585-594. 